\title{
Bisnis Bank Syariah : Telisik Faktor Pengaruh Profit Distribution Management
}

\author{
Ardiani Ika Sulistyawati ${ }^{1)}$, Aprih Santoso ${ }^{2 *}$, Annisa Ulfa ${ }^{3)}$ \\ 1,2,3 Fakultas Ekonomi Universitas Semarang, Jl. Soekarno Hatta Semarang \\ *Email korespondensi: aprihsantoso@usm.ac.id
}

\begin{abstract}
The objective of this research to analyze the factors that influence the Profit Distribution Management on sharia banks in Indonesia. Sample of this research is sharia banks at listed in Bank Indonesia (BI) for the period of observation of 2016 - 2019. Data were collected using by purposive sampling method to Islamic Banks which publishes financial report consistently. The number of samples in this study are 8 Islamic Banks with 128 oberservation. Test analysis using assumption of classical test, hypothesis test, and multiple regression analysis. The result that variable proportion of non-investment financing, proportion of third party fund, bank age, effectiveness of third party funds, financing riskand third party funds significantly influence profit distribution management. The results of this study is expected that more sharia banks are capable of perform management and development of Islamic banks products based on results in accordance with the provisions of islamic sharia.
\end{abstract}

Keywords: profit, investment financing, bank age, fund, risk

\begin{abstract}
Abstrak
Tujuan penelitian untuk menganalisis faktor-faktor yang mempengaruhi Manajemen Distribusi Laba pada bank syariah di Indonesia. Sampel penelitian ini adalah bank syariah yang terdaftar di Bank Indonesia (BI) untuk periode pengamatan 2016 - 2019. Data dikumpulkan dengan menggunakan metode purposive sampling kepada Bank Syariah yang menerbitkan laporan keuangan secara konsisten. Jumlah sampel dalam penelitian ini adalah 8 Bank Syariah dengan 128 oberservasi. Analisis uji menggunakan uji asumsi klasik, uji hipotesis, dan analisis regresi berganda. Hasil penelitian menunjukkan bahwa proporsi variabel pembiayaan non investasi, proporsi dana pihak ketiga, umur bank, efektivitas dana pihak ketiga, risiko pembiayaan, dan dana pihak ketiga berpengaruh signifikan terhadap manajemen distribusi laba. Hasil penelitian ini diharapkan lebih banyak bank syariah yang mampu melakukan manajemen dan pengembangan produk bank syariah berdasarkan hasil sesuai dengan ketentuan syariah islam.
\end{abstract}

Kata kunci: laba, pembiayaan investasi, umur bank, dana, risiko

Saran sitasi: Sulistyawati, A. I., Santoso, A., \& Ulfa, A. (2021). Bisnis Bank Syariah : Telisik Faktor Pengaruh Profit Distribution Management. Jurnal Ilmiah Ekonomi Islam, 7(01), 311-320. doi:http://dx.doi.org/10.29040/jiei.v7i1.1717

DOI: http://dx.doi.org/10.29040/jiei.v7i1.1717

\section{PENDAHULUAN}

Peran perbankan syariah sebagai lembaga keuangan memiliki fungsi yang sama dengan perbankan konvensional yaitu fungsi intermediasi keuangan. Langkah strategis yang dapat ditempuh oleh bank syariah di Indonesia dalam rangka meningkatkan kinerjanya di ekonomi global, salah satunya adalah dengan cara meningkatkan kinerja keuangan perbankan syariah dalam negeri. Peningkatan kinerja keuangan membawa dampak yang sangat luar biasa dalam usaha bank menjaga kepercayaan deposannya agar tetap menggunakan jasanya. Prinsip utama yang harus dikembangkan oleh bank syariah dalam meningkatkan kinerja keuangan adalah kemampuan bank syariah dalam melakukan pengelolaan dana.

Wulandari. et. al. (2013), bank syariah menghimpun dana dari masyarakat yang kelebihan dana dan menyalurkan kembali dan tersebut kepada masyarakat yang kekurangan dana. Dalam proses penghimpunan dana maupun penyaluran dana, bank syariah menerapkan sistem bagi hasil berdasarkan 
prinsip Profit Sharing maupun Revenue Sharing sesuai dengan fatwa Dewan Syariah Nasional MUI dalam peraturan DSN N0:15/DSN-MUI/IX/2000. Sistem bagi hasil membuat besar kecilnya keuntungan yang diterima nasabah deposan (penabung/shahibul maal) mengikuti besar kecilnya keuntungan bank syariah. Penyaluran dana deposan yang terkumpul akan ditempatkan oleh bank syariah ke sektor-sektor usaha produktif (pembiayaan) yang menghasilkan profit (Bank Indonesia). Hasil usaha semakin tinggi maka semakin besar pula keuntungan yang dibagikan bank kepada deposannya. Namun jika keuntungannya kecil otomatis semakin kecil pula keuntungan yang dibagikan bank kepada deposannya.

Syariah Enterprise Theory menjelaskan bahwa Allah Subhanahu Wata'ala sebagai pusat segala sesuatu dan menjadi pusat tempat kembalinya manusia dan alam semesta. Oleh karena itu, manusia di sini hanya sebagai wakil Allah (khalifatul fil ardh) yang memiliki konsekuensi untuk patuh terhadap semua hukum-hukum Allah dalam membawa misi menciptakan dan mendistribusikan kesejahteraan bagi manusia dan alam. Teori ini menyatakan bahwa harta adalah milik Allah dan hanya titipan untuk manusia dan harus dikelola sebaik mungkin. Harta yang dimiliki tidak boleh ditimbun dan harus dikelola dengan baik agar harta tersebut dapat berputar, produktif dan bermanfaat bagi orang lain (Wulandari et. al. (2013). Peran perbankan syariah yang menjalankan segala kegiatannya berdasarkan aturan Al-Quran dan Hadist, sehingga perlu untuk bank syariah menyalurkan dana yang dihimpun sebagai pembiayaan kepada pihak lain yang membutuhkan.

Annisa et. al. (2015) menyatakan bahwa salah satu sumber dana yang digunakan untuk pembiayaan adalah simpanan Dana Pihak Ketiga (DPK).Selain itu, Husain et. al. (2015) menyebutkan bahwa pengelolaan dana pihak ketiga yang sesuai dengan syariah Islam memang mengutamakan adanya prinsip amanah yang dilakukan secara berkesinambungan dan tanpa memerlukan awarness, hal ini dikarenakan semua yang dilakukan manusia dimuka bumi ini adalah ibadah. Dalam pelaporan keuangan perbankan posisi Dana Pihak Ketiga (DPK) disajikan pada posisi Liability sebagai kategori kewajiban perbankan sedangkan asset yang akan ditopang oleh DPK disajikan pada akun pembiayaan yang tergolong kedalam asset lancar (Husain et. al. (2015).

Kesadaran pihak pengelola perbankan akan label syariah yang diembannya merupakan tanggung jawab yang mesti diimplementasikan dalam pengelolaan yang berhubungan dengan fungsi intermediasi bank. Hasil penelitian Farrok et. al (2015) dan Mulyo dan Mutmainah (2013) menyebutkan bahwa Proporsi Dana Pihak Ketiga (PDPK) faktor yang berpengaruh signifkan terhadap pengelolaan distribusi bagi hasil (profit distribution management. Namun hal ini bertentangan dengan Wafaretta et. al. (2015) yang mengungkapkan bahwa PDM justru tidak dipengaruhi Dana Pihak Ketiga.

Pembagian keuntungan bank syariah kepada deposan berdasarkan nisbah yang disepakati setiap bulannya disebut Profit Distribution (PD). PD diatur berdasarkan produk yang menjadi pilihan deposan terhadap bank, serta persetujuan nisbahnya. Pihak manajamen bank syariah harus memperhatikan tingkat PD melalui pengelolaannya (profit distribution management). Profit Distribution Management (PDM) dapat diartikan sebagai aktivitas yang dilakukan manajer dalam mengelola pendistribusian laba untuk memenuhi kewajiban bagi hasil bank syariah kepada deposannya (Mulyo dan Mutmainah (2013). Fenomena yang terjadi menunjukkan bahwa bank syari'ah tidak melakukan profit distribution secara sebenarnya, melainkan melakukan Profit Distribution Management (PDM) yang mengacu pada suku bunga bank konvensional (Fitriyana et. al. 2018).

Berdasarkan uraian diatas dan perbedaan hasil penelitian maka penelitian ini dilakukan untuk menguji kembali factor-faktor yang mempengaruhi profit distribution management bank syariah di Indonesia periode 2016 - 2019. Penelitian ini menggunakan variabel Proporsi Pembiayaan Non Investasi (PPNI), Proporsi Dana Pihak Ketiga (PDPK), Umur Bank (UB), Efektivitas Dana Pihak Ketiga (EDPK), Risiko Pembiayaan (RP), dan Dana Pihak Ketiga (DPK) sebagai variabel independen.

\section{KERANGKA TEORI ATAU KONSEP} Pengaruh Proporsi Pembiayaan Non Investasi (PPNI) Terhadap Profit Distribution Management (PDM)

Proporsi pembiayaan Non Investasi (PPNI) bank syariah mengacu pada pembiayaan dengan tingkat tetap (sisi piutang). Pembiayaan Non Investasi pada bank syariah dilakukan dengan akad Murabahah, Salam, Istishna' dan Ijarah. Biasanya instrumen tersebut berada dalam jangka waktu 3 bulan hingga 8 tahun. Pembiayaan jenis ini menggunakan tingkat 


\section{Jurnal Ilmiah Ekonomi Islam, 7(01), 2021, 313}

harga dan keuntungan yang disepakati di awal kontrak.

PPNI dari sebuah bank Islam, khususnya yang eksposur pembiayaan dengan tingkat bunga tetap, dapat mempengaruhi sejauh mana bank mengelola distribusi laba kepada deposan. PPNI dihitung dengan menggunakan rasio Loan Asset to Total Asset (LATA). LATA bank syariah mengacu pada pembiayaan dengan tingkat tetap (sisi piutang). Penelitian Farrok et. al (2015), Mulyo dan Mutmainah (2013) dan Kartika et.al (2013) menunjukkan bahwa Proporsi Pembiayaan Non Investasi (PPNI) dapat mempengaruhi Profit Distibution Management (PDM) pada bank syariah.

Dari uraian diatas dapat dirumuskan hipotesis sebagai berikut :

$\mathrm{H}_{1}$ : Proporsi Pembiayaan Non Investasi (PPNI) berpengaruh terhadap Profit Distribution Management (PDM).

\section{Pengaruh Proporsi Dana Pihak Ketiga (PDPK)} Terhadap Profit Distribution Management (PDM)

Proporsi Dana Pihak Ketiga (EPDK) merupakan variabel yang menggambarkan seberapa besar kebergantungan bank terhadap dana nasabah. Dana merupakan masalah utama bagi bank sebagai lembaga keuangan, karena dana yang dihimpun dari masyarakat ternyata merupakan dana terbesar yang paling diandalkan oleh bank. Jika dana tidak cukup, bank tidak mampu melakukan fungsinya dengan maksimal atau bahkan menjadi tidak berfungsi sama sekali. Hal tersebut bila dikaitkan dengan Shariah Enterprise Theory dimana bank akan menjalankan amanat sesuai dengan tanggung jawabnya yaitu memaksimalkan tingkat bagi hasil, maka tingak PDM pun meningkat seiring meningkatnya Deposits. Farrok et. al (2015) yang membuktikan bahwa bank syariah dengan proporsi dana pihak ketiga lebih kecil dari dana pemegang saham yang cenderung tidak mengelola profit distribution management yang mengacu pada suku bunga. Farrok et. al (2015) dan Mulyo dan Mutmainah (2013) menyatakan bahwa Proporsi Dana Pihak Ketiga (PDPK) berpengaruh terhadap Profit Distribution Management (PDM).

$\mathrm{H}_{2}$ : Proporsi Dana Pihak Ketiga (PDPK) berpengaruh terhadap Profit Distribution Management (PDM)

\section{Pengaruh Umur Bank Terhadap Profit Distribution Management (PDM)}

Farrok et. al (2015) bank yang baru berdiri sama dengan perusahaan yang baru berdiri. Bank yang baru berdiri tersebut memiliki kekurangan informasi mengenai kondisi bank itu sendiri. Bank yang baru berdiri harus mampu melakukan tindakan yang membangun kepercayaan bagi para stakeholdernya. Farrok et. al (2015) berpendapat bahwa susah bagi perusahaan untuk memulai operasi usahanya terutama mendapatkan laba di awal-awal tahun operasinya. Bagi bank syariah ini merupakan hal yang buruk terutama karena penggunaan sistem bagi hasil. Susahnya mendapatkan laba akan membuat bagi hasil semakin kecil, hal ini akan mengakibatkan deposan menarik dananya dan memindahkannya pada bank yang memberikan return lebih baik (displacement fund). Wafaretta et. al. (2015) mengatakan bahwa ketika umur bank lama maka pendapatannya besar yang otomatis distribusi keuntungannya juga banyak. Bila dikaitkan dengan sharia enterprise theory, maka demi mengurangi risiko ini, bank syariah akan menjaga atau meningkatkan tingkat PDM untuk membangun kepercayaan atas deposan sesuai amanah yang dijalankannya. Penelitian Farrok et. al (2015), Wafaretta et. al. (2015), Norr. et. al. (2013) , Muyassaroh dan Saputra (2015) dan Sholfyta dan Filianti (2018) menyatakan umur bank (UB) berpengaruh terhadap Profit Distribution Management (PDM)

$\mathrm{H}_{3}$ : Umur Bank (UB) berpengaruh terhadap Profit Distribution Management (PDM)

Pengaruh Efektivitas Dana Pihak Ketiga (EDPK) terhadap Profit Distribution Management (PDM)

Efektivitas dana pihak ketiga (EDPK) merupakan cerminan dari fungsi intermediasi bank, yaitu dalam menyalurkan dana pihak ketiga ke pembiayaan. EDPK dapat diukur dengan Financing to Deposit Ratio (FDR).Standar terbaik FDR menurut Bank Indonesia adalah 85 - $110 \%$ (Mayangsari. et. al. 2014). Semakin baik tingkat kesehatan bank, karena pembiayaan yang disalurkan bank lancar, sehingga pendapatan bank semakin meningkat.Meningkatnya profit distribution management (PDM) dikarenakan bank akan mempertahankan customer relationship dengan tingkat bagi hasil yang tinggi, maka akan mengurangi resiko displacement fund. Penelitian Mulyo dan Mutmainah (2011), Wafaretta et. al. (2015) dan Kartika et.al (2013) EDPK berpengaruh dignifikan terhadap PDM.

$\mathrm{H}_{4}$ : Efektivitas Dana Pihak Ketiga (EPDK) berpengaruh terhadap Profit Distribution Management (PDM). 
Pengaruh Risiko Pembiayaan (RP) Terhadap Profit Distribution Management (PDM)

Tingkat bagi hasil (profit distribution) yang akan diterima nasabah akan sangat bergantung pada jumlah dana yang disalurkan dan seberapa baik kualitas pembiayaan yang diberikan bank, karena hal ini akan mempengaruhi perolehan laba dari penggunaan dana nasabah, hal ini bisa diindikasikan melalui tingkat Risiko Pembiayaan (RP) yang diukur dengan rasio NPF. Semakin tinggi rasio ini, menunjukkan kualitas pembiayaan bank syariah semakin buruk. Standar terbaik NPF menurut Bank Indonesia adalah bila NPF berada dibawah $5 \%$ (Mayangsari. et. al. 2014). Semakin baik kualitas pembiayaan yang disalurkan bank, makin kecil tingkat NPF. Apabila Risiko Pembiayaan (RP) semakin besar, maka bagi hasil semakin rendah. Bertambahnya tingkat PDM dikarenakan tingkat profit distribution yang diperoleh deposan sudah rendah. hasil penelitian Mulyo dan Mutmainah (2013) dan Muyassaroh dan Saputra (2015) yang menyatakan bahwa Efektivitas Dana Pihak Ketiga (EDPK) yang diproksikan dengan NPF berpengaruh terhadap Profit Distribution Management (PDM)

$\mathrm{H}_{5}$ : Risiko Pembiayaan (RP) berpengaruh terhadap Profit Distribution Management (PDM)

Pengaruh Dana Pihak Ketiga (DPK) Terhadap Profit Distribution Management (PDM)

Dana Pihak Ketiga (DPK) adalah simpanan nasabah berupa tabungan, giro serta deposito dalam rupiah dan valuta asing yang dihimpun oleh bank syariah pada saat tertentu, yang dinyatakan dalam milyaran rupiah. Besar kecilnya DPK yang berhasil dihimpun oleh suatu bank merupakan ukuran dalam tingkat kepercayaan masyarakat terhadap bank tersebut (Mayangsari. et. al. 2014)|. Semakin tinggi jumlah angka DPK, semakin mempermudah pihak bank untuk mencapai profit, sehingga profit distribution yang diberikan manajemen bank semakin tinggi. Andraeny (2011) menjelaskan bahwa DPK berpengaruh signifikan terhadap volume pembiayaan berbasis bagi hasil pada perbankan syariah di Indonesia. Wafaretta et. al. (2015) menyatakan bahwa Dana Pihak Ketiga (DPK) berpengaruh positif terhadap Profit Distribution Managament (PDM). Berdasarkan sharia enterprise theory bahwa bank syariah bertanggung jawab mengelola dana dengan baik dari deposan dan bertanggung jawab mengelola distribusi bagi hasil dengan baik. Semakin tinggi dana yang terkumpul dari pihak ketiga (masyarakat) akan semakin besar pula risiko dalam pengelolaan dana yang yang dihadapi bank syariah sehingga dapat meningkatkan pengelolaan distribusi bagi hasil kepada deposan.

$\mathrm{H}_{6}$ : Dana Pihak Ketiga berpengaruh terhadap Profit Distribution Management (PDM).

\section{METODE PENELITIAN}

\section{Populasi dan Sampel}

Populasi penelitian adalah Bank Umum Syariah (BUS) yang terdaftar di Bank Indonesia tahun 20162019. Sampel penelitian diperoleh dari laporan keuangan tahunan sejumlah 128 Bank syariah yang tergolong BUS dan terdaftar di Bank Indonesia periode 2016-2019. (b) Mempublikasikan laporan keuangan triwulanan periode 2016-2019 secara konsisten dan dipublikasikan pada Otoritas Jasa Keuangan (www.ojk.go.id) atau website Bank Indonesia (www.bi.go.id).

\section{Metode Analisis Data}

Analisis data menggunakan : uji statistik deskriptif, uji normalitas (uji statistik KolmogrovSmirnov), uji multikoloniearitas, uji heteroskedastisitas (uji Park) dan uji hipotesis (uji F) dan analisis regresi linier berganda. Model persamaan analisis regresi linier berganda, yaitu :

\section{PDM $=\mathbf{a}+\beta_{1}$ PPNI $+\beta_{2}$ PDPK $+\beta_{3} \mathrm{UB}+\beta_{4} \mathbf{X}_{4}+$ $\beta_{5} \mathrm{EDPK}+\beta_{6} \mathrm{DPK}+\varepsilon$}

\section{HASIL DAN PEMBAHASAN}

a. Analisis Statistik Deskriptif

Proporsi Pembiayaan Non Investasi (PPNI) yang diproksikan dengan Loan Asset to Total Asset (LATA) memiliki nilai terendah yang ditunjukkan oleh PT.Bank Panin Dubai Syariah (BDPS) pada triwulan III tahun 2018 sebesar 5,77, sedangkan nilai tertinggi ditunjukkan oleh PT. Bank Mega Syariah (BMS) sebesar 84,93 pada triwulan I tahun 2016. Nilai ratarata (mean) dan standar deviasinya masing-masing sebesar 50,0575 dan 18,92558.

Proporsi Dana Pihak Ketiga (PDPK) merupakan variabel yang dirumuskan dengan Dana Pihak Ketiga (DPK) dibagi dengan Total Asset bank syariah memiliki nilai terendah yang ditunjukkan oleh PT. Maybank Syariah Indonesia (MBSI) sebesar 25,09 pada triwulan III tahun 2016, sedangkan nilai tertinggi ditunjukkan oleh PT. Bank Syariah Mandiri (BSM) sebesar 92,33 pada triwulan III tahun 2017. Nilai ratarata (mean) dan standar deviasinya masing-masing sebesar 75,8859 dan 14,24482. 
Umur Bank (UB) yang dirumuskan dengan bulan dalam periode penelitian dikurangkan dengan bulan berdirinya bank memiliki nilai terendah yang ditunjukkan oleh PT. Maybank Syariah Indonesia (MBSI) sebesar 2,42 pada triwulan I tahun 2016, sedangkan nilai tertinggi ditunjukkan oleh PT. Bank Syariah Mandiri (BSM) sebesar 17,08 pada triwulan IV tahun 2019. Nilai rata-rata (mean) dan standar deviasinya masing-masing sebesar 7,1094 dan 3,77749 .

Efektivitas Dana Pihak Ketiga yang diproksikan dengan Financing Deposit Ratio (FDR) memiliki nilai terendah yang ditunjukkan oleh PT. Bank Syariah Mandiri (BSM) sebesar 79,19 pada triwulan IV tahun 2019, sedangkan nilai tertinggi ditunjukkan oleh PT. Maybank Syariah Indonesia (MBSI) sebesar 257,08 pada triwulan III tahun 2016. Nilai rata-rata (mean) dan standar deviasinnya masing-masing sebesar 103,3455 dan 29,52795.

Risiko Pembiayaan (RP) yang diproksikan dengan Net Perfoming Financing (NPF) Gross memiliki nilai terendah yang ditunjukkan oleh PT. Bank Central Asia Syariah (BCAS) Syariah sebesar 0,01 pada triwulan II tahun 2016, sedangkan nilai tertinggi ditunjukkan oleh PT.Maybank Syariah Indonesia (MBSI) sebesar 43,99 pada triwulan IV tahun 2019. Nilai rata-rata (mean) dan standar deviasinnya masing-masing sebesar4,4348 dan 6,28352 .

Dana Pihak Ketiga (DPK) yang dirumuskan dengan Total (Giro, Tabungan dan Deposito) memiliki nilai terendah yang ditunjukkan oleh PT.Maybank Syariah Indonesia (MBSI) sebesar 0,53 pada triwulan III tahun 2016, sedangkan nilai tertinggi ditunjukkan oleh PT. Bank Syariah Mandiri (BSM) sebesar 69,95 pada triwulan IV tahun 2019. Nilai ratarata (mean) dan standar deviasinnya masing-masing sebesar 13,7053 dan 18,21223.

Profit Distribution Management (PDM) yang diproksikan dengan Asset Spread memiliki nilai terendah yang ditunjukkan oleh PT. Maybank Syariah Indonesia (MBSI)sebesar -20,26 pada triwulan IV tahun 2018 dan triwulan IV tahun 2016, sedangkan nilai tertinggi ditunjukkan oleh PT. Maybank Syariah Indonesia (MBSI) pada triwulan I tahun 2016 sebesar 7,83. Nilai rata-rata (mean) dan standar deviasinya masing-masing sebesar 5,532 dan 3,38860.

\section{b. Hasil Uji Asumsi Klasik}

Hasil pengujian statistik One-Sample Kolmogrov-Smirnov menunjukkan nilai Kolmogrov-
Smirnov Z sebesar 1,111 dan Asymp. Sig sebesar 0,169 . Artinya nilai tersebut lebih besar dari 0,05 dengan demikian dapat disimpulkan nilai residual terdistribusi normal atau memenuhi syarat uji normalitas Hasil pengujian statistik run test menunjukkan Asymp. Sig. 0,723 . > 0,05 artinya tidak ada autokorelasi positif atau negatif, sehingga tidak terjadi autokorelasi antar nilai residual. Hasil uji multikoloniearitas semua variabel independen memiliki nilai tolerance bergerak dari 0,106 sampai dengan 0,724>0,10 dan nilai VIF bergerak dari 1,381 sampai dengan $9,464<10$ maka tidak terjadinya Multikoloniearitas. Hasil uji heteroskedastisitas menggunakan uji Park menunjukkan semua variabel independen nilai sig. nya bergerak antara 0,225 sapai dengan $0,905>0,05$ sehingga tidak terjadi heteroskedastisitas.

Hasil persamaan regresi sebagai berikut :

\section{PDM $=17,339+0,32$ PPNI - 0,113PDPK + 1,222LnUB - 0,103EDPK- 0,521RP + 3,156 $(1 /(\mathrm{DPK} * \mathrm{DPK})+\varepsilon$}

Dari persamaan regresi linier berganda di atas dapat dijelaskan bahwa Proporsi Pembiayaan Non Investasi (PPNI), Proporsi Dana Pihak Ketiga (PDPK), Umur Bank (UB), Efektivitas Dana Pihak Ketiga (EDPK), Risiko Pembiayaan (RP) dan Dana Pihak Ketiga (DPK) berpengaruh terhadap Profit Distribution Management (PDM).

\section{c. Uji Hipotesis}

Dari hasil perhitungan diperoleh nilai $\mathrm{F}$ sebesar 63,519dan signifikansi sebesar $0,000<0,05$ maka hipotesis diterima artinya terdapat pengaruh secara simultan antara Proporsi Pembiayaan Non Investasi (PPNI), Proporsi Dana Pihak Ketiga (PDPK), Umur Bank (UB), Efektivitas Dana Pihak Ketiga (EDPK), Risiko Pembiayaan (RP) dan Dana Pihak Ketiga (DPK) terhadap Profit Distribution Mangament (PDM).

\section{d. Uji koefisien determinasi}

Nilai adjusted $\mathrm{R}$ square diperoleh sebesar 0,747. Hal ini berarti bahwa 74,7 \% Profit Distribution Mangament (PDM) dijelaskan oleh Proporsi Pembiayaan Non Investasi (PPNI), Proporsi Dana Pihak Ketiga (PDPK), Umur Bank (UB), Efektivitas Dana Pihak Ketiga (EDPK), Risiko Pembiayaan (RP) dan Dana Pihak Ketiga (DPK) sedangkan sisanya 25,3 $\%$ dijelaskan oleh variabel-variabel lain diluar penelitian. 


\section{e. Pembahasan}

\section{Pengaruh Proporsi Pembiayaan Non Investasi (PPNI) Terhadap Profit Distribution Management (PDM)}

Berdasarkan output SPSS 23, uji t untuk Proporsi Pembiayaan Non Invetasi (PPNI) nilai probabilitas signifikansinya $0,001<0,05$ berarti berpengaruh terhadap profit Distribution Management (PDM) sehingga $\mathrm{H}_{1}$ diterima artinya semakin tingggi PPNI berakibat tinggi pula kemampuan bank syariah untuk mengelola distribusi laba kepada deposen dari aset mereka yang terkonsentrasi di instrumen utang dengan bunga tetap. Jadi semakin tinggi PPNI dapat menjadi tolak ukur peningkatan PDM oleh manager bank yang bersangkutan.

Berdasarkan hasil statistik deskriptif, PPNI menunjukkan nilai maksimum sebesar $84,93 \%$ dan rata-rata sebesar $50,06 \%$, berarti tingginya tingkat return bagi nasabah. Nasabah sebagai pemilik dana yang tergolong dalam floating segment akan sangat sensitif terhadap perubahan tingkat suku bunga. Besarnya LATA menentukan tingkat dimana bank syariah melakukan PDM untuk return mismatch dalam keadaan pasar dimana terdapat perubahan suku bunga (Farrok et. al 2015). Hal ini bila dikaitkan dengan sharia enterprise theory dimana bank akan mengelola dengan baik agar harta yang terkumpul dapat berputar, produktif dan bermanfaat bagi orang lain, maka tingkat PDM pun meningkat seiring meningkatnya PPNI.

Berdasarkan laporan keuangan periode triwulan Itahun 2016 menunjukkan, PT. Bank Rakyat Indonesia Syariah (BRIS) memiliki PPNI sebesar 59,11 dan PDM sebesar 2,65, sedangkan pada triwulan I tahun 2017 menunjukkan PPNI sebesar 56,55 dan PDM sebesar 1,38, artinya PPNI lebih besar akan diikuti kenaikan pada PDM. PT. Bank Syariah Mandiri (BSM) pada periode triwulan II 2016 menunjukkan PPNI sebesar 63,12 dengan PDM sebesar 1,74. Periode triwulan II tahun 2017 menunjukkan PPNI sebesar 61,24 dan PDM sebesar 0,64, artinya apabila semakin tinggi PPNI maka PDM meningkat. PT. Maybank Syariah Indonesia (MBSI) pada periode triwulan II tahun 2016 menunjukkan PPNI sebesar 60,80 dan PDM sebesar 2,80. Periode triwulan II tahun 2017 menunjukkan PPNI sebesar 63,47 dan PDM sebesar 2,36, artinya apabila semakin tinggi PPNI akan diikuti kenaikan pada PDM. Hasil penelitian ini sejalan dengan Farrok et. al (2015), Mulyo dan Mutmainah (2013) dan Kartika et.al (2013) yang menyatakan bahwa Proporsi Pembiayaan Non Investasi (PPNI) yang diproksikan dengan LATA berpengaruh terhadap Profit Distribution Management (PDM) pada bank umum syariahnya. Namun hasil penelitian ini justru tidak sejalan dengan Wafaretta et. al. (2015) dan Muyassaroh dan Saputra (2015) yang menyatakan bahwa Proporsi Pembiayaan Non Investasi (PPNI) justru tidak berpengaruh terhadap Profit Distribution Management (PDM).

Pengaruh Proporsi Dana Pihak Ketiga (PDPK) Terhadap Profit Distribution Management (PDM)

Berdasarkan output SPSS 23, uji t untuk Proporsi Dana Pihak Ketiga nilai probabilitas signifikasinya $0,000<0,05$ berarti berpengaruh positif terhadap Profit Distribution Management (PDM) sehingga $\mathrm{H}_{2}$ diterima artinya semakin tinggi PDPK suatu bank dapat menjadi tolak ukur peningkatan PDM oleh manajer bank syariah yang bersangkutan. Hal ini bila dikaitkan dengan sharia enterprise theory dimana bank akan mengelola dengan baik agar harta yang terkumpul dapat berputar, produktif dan bermanfaat bagi orang lain, maka tingkat PDM pun akan menurun seiring meningkatnya PDPK. Hal ini terjadi karena dana dari pihak deposan yang terlalu besar, menghambat dalam pengelolaan distribusi bagi hasil tanpa secara eksplisit terdeteksi (Farrok et. al 2015).

Berdasarkan laporan keuangan periode triwulan III tahun 2016 menunjukkan PT. Bank Syariah Mandiri (BSM) dengan PDPK sebesar 82,07 dan PDM sebesar 1,47. Periode triwulan III tahun 2017 menunjukkan PDPK sebesar 92,33 dan PDM sebesar 0,77, artinya semakin tinggi PDPK maka PDM menurun. PT. BRI Syariah (BRIS) pada periode triwulan III tahun 2016 menunjukkan PDPK sebesar 83,02 dan PDM sebesar 1,73. Periode triwulan III tahun 2017 menunjukkan PDPK sebesar 83,51 dan PDM sebesar 0,24, artinya semakin tinggi PDPK maka PDM menurun. PT. BNI Syariah (BNIS) menunjukkan PDPK sebesar 80,79 dan PDM sebesar 1,10 pada periode triwulan III 2017. Periode triwulan III tahun 2018 menunjukkan PDPK sebesar 82.68 dan PDM sebesar 0,78, artinya semakin tinggi PDPK maka PDM menurun. Hasil penelitian ini konsisten dengan (Farrok et. al 2015) dan Mulyo dan Mutmainah (2013) yang menyatakan bahwa Proporsi Dana Pihak Ketiga (PDPK) berpengaruh terhadap Profit Distribution Management (PDM). Namun hasil penelitian ini justru tidak sejalan dengan hasil penelitian Kartika et.al (2013) dan Muyassaroh dan Saputra (2015) yang menyatakan bahwa Proporsi 
Dana Pihak Ketiga (PDPK) tidak berpengaruh terhadap Profit Distribution Management (PDM).

Pengaruh Umur Bank (UB) Terhadap Profit Distribution Management (PDM)

Berdasarkan output SPSS 23, uji t untuk Umur Bank (UB) nilai probabilitas signifikasinya $0,000<$ 0,05 berarti berpengaruh positif terhadap Profit Distribution Management (PDM) sehingga $\mathrm{H}_{3}$ diterima artinya semakin lama suatu bank beroperasi dapat menjadi tolak ukur peningkatan PDM oleh manajer bank syariah yang bersangkutan. Menurut Farrok et. al (2015) bank syariah yang beroperasi lebih lama cenderung mengelola distribusi bagi hasil sebagai akibat dari rendahnya pendapatan dan pembiayaan sub-optimal pada tahun-tahun tersebut. Wafaretta et. al. (2015) mengatakan bahwa ketika umur bank lama maka pendapatannya besar yang otomatis distribusi keuntungannya juga banyak.

Secara umum, bank baru masih cenderung tidak bisa memperoleh keuntungan optimal, bank baru terkadang masih mengalami kerugian atau keuntungan sangat rendah pada tahun awal beroperasi, karena risiko yang lebih tinggi, serta efisiensi yang lebih rendah dan kemampuan yang lebih rendah untuk mengelola modal (Wafaretta et. al. 2015). Selain itu, investasinya akan membutuhkan waktu yang cukup lama untuk bisa menghasilkan keuntungan, sehingga investasi tersebut belum memberikan keuntungan yang memadai bagi bank baru (Wafaretta et. al. 2015). Hal ini bila dikaitkan dengan sharia enterprise theory dimana bank akan mengelola dengan baik agar harta yang terkumpul dapat berputar, produktif dan bermanfaat bagi orang lain, maka tingkat PDM pun akan meningkat seiring meningkatnya UB.

Berdasarkan laporan keuangan triwulan periode triwulan IV tahun 2019 PT. Bank Syariah Mandiri (BSM) menunjukkan UB sebesar 17,08 bulan dan PDM sebesar 0,58, sedangkan pada periode triwulan IV tahun 2018 menunjukkan UB sebesar 16,08 dan PDM sebesar 0,55 , artinya bahwa semakin lama suatu bank beroperasi maka PDM meningkat. PT. Bank Mega Syariah (BMS) pada periode triwulan IV tahun 2019 menunjukkan UB sesebar 12,33 dan PDM sebesar 2,62. Periode triwulan IV tahun 2018 menunjukkan UB sebesar 11,33 dan PDM sebesar 0,29 , artinya semakin lama suatu bank beroperasi maka PDM meningkat. PT. BRI Syariah (BRIS) pada periode triwulan IV tahun 2019 menunjukkan UB sebesar 8,08 dan PDM sebesar 0,94. Periode triwulan IV tahun 2018 menunjukkan UB sebesar 7,08 dan
PDM sebesar 0,75 , artinya PDM meningkat seiring lamanya suatu bank beroperasi. Penelitian ini konsisten dengan Farrok et. al (2015), Wafaretta et. al. (2015), Norr. et. al. (2013)|, Muyassaroh dan Saputra (2015) dan Sholfyta dan Filianti (2018) yang menyatakan bahwa Umur Bank (UB) berpengaruh terhadap Profit Distribution Management (PDM). Namun hasil penelitian ini justru tidak konsisten dengan hasil penelitian Mulyo dan Mutmainah (2013) dan Mayangsari. et. al. (2014) mengatakan aktivitas PDM lebih condong dilakukan sebagai hasil dari decision making yang dibuat manajer atas kondisi keuangan bank tersebut sehingga Umur Bank (UB) tidak berpengaruh terhadap Profit Distribution Management (PDM)

\section{Pengaruh Efektivitas Dana Pihak Ketiga (EDPK) Terhadap Profit Distribution Management (PDM)}

Berdasarkan output SPSS 23, uji $\mathrm{t}$ untuk Efektivitas Dana Pihak Ketiga (EDPK) nilai probabilitas signifikasinya $0,000<0,05$ berarti berpengaruh positif terhadap Profit Distribution Management (PDM) sehingga $\mathrm{H}_{4}$ diterima artinya semakin tinggi EDPK suatu bank dapat menjadi tolak ukur peningkatan PDM oleh manajer bank yang bersangkutan.

Berdasarkan hasil statistik deskripsi, EDPK menunjukkan nilai rata-rata sebesar $102,21 \%$ artinya rata-rata bank syariah sudah mampu memenuhi ketentuan Bank Indonesia tentang FDR yang baik yaitu antara 85 persen - 110 persen. Nilai FDR yang ideal menunjukkan bahwa bank syariah dalam sampel penelitian dapat menjalankan perannya sebagai lembaga financial intermediary (perantara keuangan) dengan baik. Hal ini bila dikaitkan dengan sharia enterprise theory maka bank syariah akan memaksimalkan penggunanaan dana pihak ketiga yang dikelola oleh bank sesuai denganamanah yang telah disepakati.

Berdasarkan laporan keuangan periode triwulan IV tahun 2015PT.Bank BNI Syariah (BNIS) menunjukkan EDPK sebesar 90,10 dan PDM sebesar 1,19 , sedangkan pada periode triwulan I tahun 2016 menunjukkan EDPK sebesar 86,26 dan PDM sebesar1,65, artinya semakin tinggi EDPK maka tingkat PDM menurun. PT. Bank BRI Syariah (BRIS) pada periode triwulan I tahun 2016 menujukkan EDPK sebesar 88,05 dan PDM sebesar 0,52. Periode triwulan I tahun 2016 menunjukkan EDPK sebesar 83,30 dan PDM sebesar 0,98, artinya semakin tinggi EDPK maka PDM akan menurun. Semakin efektif 
dana pihak ketiga dikelola, kecenderungan manajemen laba yang mengacu pada bunga bank konvensional semakin mengecil (Mulyo dan Mutmainah, 2013). Hasil penelitian ini konsisten dengan Mulyo dan Mutmainah (2013), Wafaretta et. al. (2015) dan Kartika et.al (2013) yang menyatakan Efektivitas Dana Pihak Ketiga (EDPK) berpengaruh terhadap Profit Distribution Management (PDM). Namun penelitian ini justru tidak sejalan dengan Muyassaroh dan Saputra (2015) dan Mayangsari. et. al. (2014) yang menyatakan Efektivitas Dana Pihak Ketiga (EDPK) tidak berpengaruh terhadap PDM.

Pengaruh Risiko Pembiayaan (RP) Terhadap Profit Distribution Management (PDM)

Berdasarkan output SPSS, uji t untuk Risiko Pembiayaan (RP) nilai probabilitas signifikasinya $0,000<0,05$ berarti berpengaruh terhadap Profit Distribution Management (PDM) sehingga $\mathrm{H}_{5}$ diterima artinya semakin rendah Risiko Pembiayaan (RP) yang diproksikan dengan NPF akan menjadi tolak ukur peningkatan PDM oleh manajer bank yang bersangkutan. Berdasarkan hasil statistik deskriptif, RP menunjukkan nilai minimum sebesar 0,01\% dengan rata-rata $4,11 \%$, artinya bank syariah telah mampu memenuhi ketentuan Bank Indonesia tentang NPF yang ideal adalah dibawah 6 persen. Semakin rendah nilai NPF menunjukkan kualitas pembiayaan bank syariah semakin baik, maka tingkat bagi hasil akan semakin tinggi. Hal ini bila dikaitkan dengan sharia enterprise theory dimana bank akan mengelola dengan baik agar harta yang terkumpul dapat berputar, produktif dan bermanfaat bagi orang lain, maka tingkat PDM pun akan meningkat seiring menurunnya RP.

Berdasarkan laporan keuangan triwulan III tahun 2016 PT. BCA Syariah (BCAS) menunjukkan RP sebesar 0,07 dan PDM sebesar 0,97, sedangkan pada periode triwulan III tahun 2017 menunjukkan RP sebesar 0,14 dan PDM sebesar 0,64, artinya semakin rendah RP maka PDM meningkat. PT. Bank Panin Dubai Syariah (BPDS) pada periode triwulan II tahun 2016 menunjukkan RP sebesar 0,57 dan PDM sebesar 2,33. Periode triwulan II tahun 2017 menunjukkan RP sebesar 0,76 dan PDM sebesar 1,64, artinya semakin rendah RP maka PDM meningkat. Penelitian ini sejalan dengan Mulyo dan Mutmainah (2013) dan Muyassaroh dan Saputra (2015) yang menyatakan Efektivitas Dana Pihak Ketiga (EDPK) yang diproksikan dengan NPF berpengaruh terhadap Profit Distribution Management (PDM). Namun Penelitian ini berbeda Mayangsari. et. al. (2014) yang menyatakan NPF tidak berpengaruh terhadap PDM.

Pengaruh Dana Pihak Ketiga (DPK) Terhadap Profit Distribution Management (PDM)

Berdasarkan output SPSS, uji t untuk Dana Pihak Ketiga (DPK) nilai probabilitas signifikasinya $0,000<$ 0,05 berarti berpengaruh positif terhadap Profit Distribution Management (PDM) sehingga $\mathrm{H}_{6}$ artinya semakin tinggi DPK yang dirumuskan dengan Total Giro, Tabungan dan Deposito dapat dijadikan tolak ukur peningkatan PDM oleh manajer bank yang bersangkutan. Menurut Andraeny (2011) menyebutkan bahwa semakin banyak aliran DPK yang masuk kedalam kas bank syariah maka akan semakin meningkatkan kegiatan pembiayaan bank. Sesuai dengan sharia enterprise theory bahwa dana yang diperoleh dari deposan harus dikelola dengan baik oleh shahibul maal (bank syariah) sehingga dapat mengoptimalkan distribusi bagi hasil dari keuntungan bank.

Berdasarkan laporan kuangan triwulan IV tahun 2018 PT. Bank Syariah Mandiri (BSM) total DPK sebesar 62,11 triliun dan PDM sebesar 0,54, sedangkan pada triwulan IV tahun 2019 total DPK sebesar 69,95 triliun dan PDM sebesar 0,58, artinya semakin besar DPK yang diterima oleh bank manajemen bank syariah maka pengelolaan distribusi bagi hasil meningkat. PT. Bank Negara Indonesia Syariah (BNIS) pada triwulan II tahun 2018 menunjukkan total DPK yang diterima sebesar 17,32 triliun dengan PDM sebesar 1,29, sedangkan pada triwulan II tahun 2019 total DPK yang diterima sebesar 21,83 triliun dan PDM sebesar 1,58, artinya semakin besar DPK yang diterima oleh bank manajemen bank syariah maka pengelolaan distribusi bagi hasil meningkat. Hasil penelitian ini konsisten dengan Wafaretta et. al. (2015) yang menyatakan bahwa DPK berpengaruh positif terhadap PDM. Namun hasil penilitian ini justru tidak konsisten dengan hasil penelitian Mayangsari. et. al. (2014) yang menyatakan bahwa DPK tidak berpengaruh terhadap PDM.

\section{PENUTUP}

Proporsi Pembiayaan Non Investasi (PPNI), Proporsi Dana Pihak Ketiga (PDPK), Umur Bank (UB), Efektivitas Dana Pihak Ketiga (EDPK), Risiko Pembiayaan (RP) dan Dana Pihak Ketiga (DPK) berpengaruh terhadap Profit Distribution Management (PDM). 
Dalam penelitian ini disarankan yaitu bagi Bank Umum Syariah, untuk meningkatkan kinerja manajemen dengan lebih baik dan mengembangkan produk-produk perbankan syariah yang berbasis bagi hasil sesuai dengan ketentuan syariah islam dan bagi Deposan agar dapat lebih memahami karakteristik perbankan syariah.

\section{DAFTAR PUSTAKA}

Andraeny, Dita. (2011). Analisis Pengaruh Dana Pihak Ketiga, Tingkat Bagi Hasil, dan Non Perfoming Financing Terhadap Volume Pembiayaan Berbasis Bagi Hasil Pada Perbankan Syariah di Indonesia. Simposium Nasional Akuntansi XIV.

Annisa, Lintang Nurul \& Yaya, Rizal. (2015). Pengaruh Dana Pihak Ketiga, Tingkat Bagi Hasil dan Non Perfoming Financing Terhadap Volume dan Porsi Pembiayaan Berbasis Bagi Hasil Pada Perbankan Syariah di Indonesia.. SHARE. 4 (1) : 79-104. DOI $\quad$ :10.22373/share.v4i1.754. https://jurnal.ar-

raniry.ac.id/index.php/Share/article/view/\%2375 4

Farook, Sayd, M.Kabir Hassn, \& Gregory Clinch. (2012). Profit Distribution Management by Islamic Banks : An Empirical Investigation. The Quarterly Review of Economics and Finance 52. 333-347.

https://www.academia.edu/24055498/Profit_dist ribution_management_by_Islamic_banks_An_e mpirical_investigation

Fitriyana, Ardiyani, K., Sutrisno, CR. (2018). Profit Distribution Management Pada Bank Syariah. MALIA: Journal of Islamic Banking and Finance. 2 (1) 31-46. DOI : 10.21043/malia.v2i1.4758.

https://journal.iainkudus.ac.id/index.php/syirkah /article/view/4757

Husain, Saddan \& Abdullah, Wahyudin. (2015). Metafora Amanah Pengelolaan Dana Pihak Ketiga (DPK) Sebagai Penopang Asset Perbankan Syariah Ditinjau Aspek Trilogi Akuntabilitas : Studi Kasus Pada PT. Bank BNI Syariah Cabang Makasar. Iqtisaduna. 1 (2). 4064. DOI : 10.24252/iqtisaduna.v1i2.1193. http://journal.uin-

alauddin.ac.id/index.php/Iqtisaduna/article/view/ 1193
Kartika, Septyana Bella \& Adityawarman. (2014). Analisis Faktor-Faktor yang Mempengaruhi Profit Distribution Management : Studi Empiris Bank Umum Syariah di Indonesia Periode 2009 - 2012, Diponegoro Accounting Journal of $\begin{array}{llll}\text { Accounting. } & 3 & \text { (2). } & \text { 1-15. }\end{array}$ https://ejournal3.undip.ac.id/index.php/accounti ng/article/view/6170.

Mayangsari.S., Robert Kristaung, Muhammad Zilal Hamzah, Eleonora Solfilda, Deasy Aseanti, Christina Dwi Astuti, Erliana Banjarnahor. (2014). Faktor-Faktor yang Mempengaruhi Profit Distribution Management Atas Simpanan Deposan Pada Bank Syariah di Indonesia, Proceeding The $2^{\text {nd }}$ Corporate Sustainable Conference: Theme The Green Economy and Demographic Challenges for Sustainable Development. Jakarta : Lembaga Penerbit Fakultas Ekonomi Univesitas Trisakti.

Meilani, Maidha Tri dan Setiawan Iwan. (2012). Analisis Pengelompokan (Clustering) kinerja bank syariah di Indonesia Berdasarkan Kinerja Keuangan, Jurnal Ekonomi Keuangan Perbankan dan Akuntansi. 4 (1). 67-81. https://jurnal.polban.ac.id/ojs

Mulyo, Gagat Panggah \& Mutmainah, Siti. 2013. Faktor-Faktor yang Mempengaruhi Profit Distribution Management Pada Bank Syariah di Indonesia Periode 2008-2009, Jurnal Ekonomi, Manajemen dan Akuntansi Islam (IMANESI). 1 (1),

DOI: https://doi.org/10.34202/imanensi.1.1.201 3.31-41.

https://jurnal.fordebi.or.id/index.php/home/articl e/view/5

Muyassaroh dan Saputra, Bambang. 2015. Faktor Faktor Yang Mempengaruhi Profit Distribution Management Pada Bank Syariah di Indonesia Periode 2009-2013, Jurnal Akuntansi Manajemen Madani. 1 (1), 51-72. https://ejamm.stiemadani.ac.id

Noor, Nurul Syazwani Mohd \& Sulong, Zunaidah. (2013). An Empirical Analysis of Profit Distribution Management Decisions in Malasyian Islamic Banks, Proceeding of

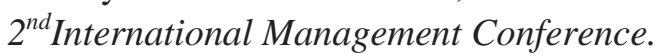

Sholfyta, Adlina dan Filianti, Dian. (2018). FaktorFaktor Yang Memengaruhi Profit Distribution Management Bank Umum Syariah Di Indonesia Periode 2011-20161). Jurnal Ekonomi Syariah Teori dan Terapan. 5 (11), 971- 986 https://ejournal.unair.ac.id > JESTT 
Jurnal Ilmiah Ekonomi Islam, 7(01), 2021, 320

Wafaretta, Vega., Rosidi \& Aulia Fuad Rahman. (2015). The Impact of Banks Characteristics on Profit Distribution Management od Islamic Banks". 3rd Global Conference on Business and Social Science-2015, GCBSS-2015, 16- 17 December 2015, Kuala Lumpur, Malaysia
Wulandari, WA \& Kiswanto. 2013 Faktor-Faktor yang Mempengaruhi Pembiayaan Berbasis Bagi Hasil (Profit and Loss Sharing). Jurnal Review Akuntansi dan Keuangan. 3 (2). 437-445. http://ejournal.umm.ac.id/index.php/jrak/article/ view/2111/2265.

DOI: https://doi.org/10.22219/jrak.v3i2.2111 | Abstract views : 824 | pdf views : 824 | 